\title{
Young and emerging African evaluators' need for gender responsive evaluation training
}

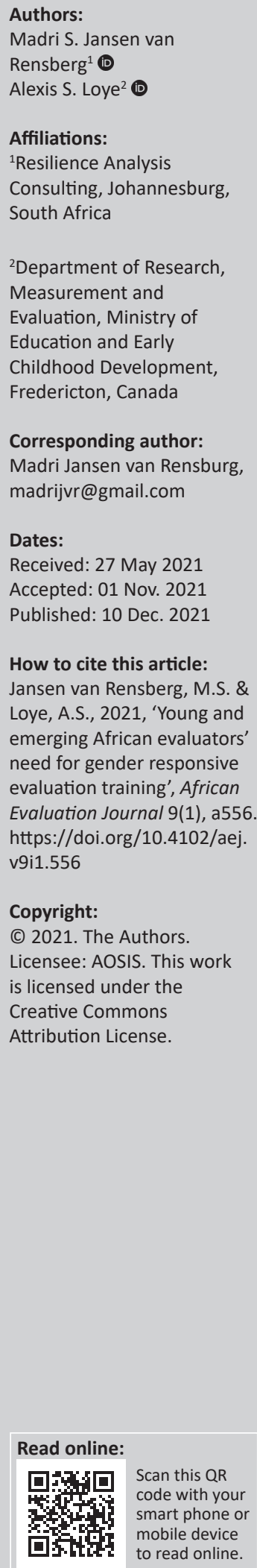

Background: The Global Evaluation Agenda 2020 calls for evaluation of Sustainable Development Goals (SDGs) within an equity-focused and gender-responsive lens. Most of the methodologies and materials come from the Global North. However, gender issues and evaluation capacity in the Global North do not necessarily match with those in the Global South. The Global South has rich experiences related to equity and gender. An important group to target to build capacity is young and emerging evaluators (YEEs).

Objectives: This study investigated the gender responsive evaluation training experiences and needs of YEEs in Africa.

Method: A total of 72 respondents completed an online survey that was administered over a 7-day period. The quantitative survey was self-administered in French and English, and was distributed through existing Voluntary Organisation for Professional Evaluation (VOPEs) and youth evaluators forums.

Results: Respondents were from 23 African countries. Most of the respondents were YEEs, although many of the respondents did not self-identify as an YEE. One-third of respondents have participated in training programmes on gender responsive evaluation or a gender focus on evaluation. Virtual trainings have not been used. Topics included evaluating gender focussed interventions and gender responsive aspects of evaluation studies in general (including applying gender perspective to all types of policies, and participatory approaches to ensure gender equity).

Conclusion: This study has practical value for training and mentoring of YEEs in gender focused evaluations in Africa. It will contribute to efforts of the South-to-South project and global efforts that ensure that 'no one is left behind' from a gender lens.

Keywords: gender responsive evaluations; young and emerging evaluator; VOPE; Africa; global South; YEE; EFGR evaluations.

\section{Introduction}

The Global Evaluation Agenda 2020 calls for every member of EvalPartners to play a role in attaining EvalVision2020 (EvalPartners 2016). This includes that Voluntary Organisations for Professional Evaluation (VOPEs) become more influential in enabling the environment for evaluation within countries or regions with the overriding message of the Sustainable Development Goals (SDGs) 'to leave no one behind' (United Nations 2015). As gender is a social construct, it is important to understand this context to be able to adopt an evaluation plan that is adequate not only for data collection but also for understanding the results and their use to improve the everyday life of women, children, the elderly and other vulnerable groups (Loye 2019). Furthermore, young and emerging evaluators (YEEs) globally play an important role in evaluations by not only having their voices included in the evaluation process but also by producing high quality evaluations (EvalYouth 2016). Hence, developing the capacity of YEEs to undertake high quality evaluations is imperative.

\section{The need for gender responsive evaluation skills in Africa}

Women and other civil society organisations around the world have developed strategies and methodologies to mainstream gender in development, following directions from Beijing Platform (UN Women 1995) and other international agreements. These experiences have seldom been applied to evaluation. However, there have been global and regional initiatives that introduce an equity focused and gender responsive (EFGR) approach to evaluation (Chigateri \& Saha 2016; Espinosa 2013; United Nations Evaluation Group 2014; UN Women 
2015). Most of the methodologies, tools and learning systems on EFGR evaluation available to VOPEs come from the Global North. Although the Global South has rich experiences related to equity and gender, they are not fully mainstreamed. On national level, various diagnostic studies of National Evaluation Systems (i.e. plans and frameworks) have been conducted. These include countries such as: Uganda, Benin and South Africa (Jansen van Rensburg \& Blaiser-Mapitsa 2017; Tirivanhu \& Jansen van Rensburg 2018; Wokadala 2016).

The VOPEs representing three regions from the Global South (Africa, Latin America and Caribbean and Southeast Asia) developed curricula and guidelines for mainstreaming a gender responsive approach into evaluation. These capacity building efforts focus on existing best practices and innovative ways to develop technical and leadership competencies for promotion and application of the EFGR approach. The African Gender and Development Evaluators Network (AGDEN), established in 2002 by the African Evaluators Association (AfrEA) and United Nations Development Fund for Women (UNIFEM), now UN Women, aims to strengthen the effectiveness and gender responsiveness of development programmes and projects to human rights. African Gender and Development Evaluators Network was the African partner of this project.

The first phase of the South-to-South project focussed on the current capacity and gaps as identified by established evaluators in Africa. Two AGDEN curricula were revised and combined to reflect the new information on local needs. There are different target audiences for the development of gender responsive evaluation skills. One of the most important intersections would be in the development of YEEs. During the second phase of this initiative, the needs of YEEs were explored to enable better targeting of training events in Africa related to gender and culturally sensitive evaluations. This article focuses on the second part of the project, investigating the training experiences and needs of YEEs from Africa.

\section{Targeting young and emerging evaluator skills development in Africa}

In meeting evaluation standards in South Africa there is a gap in evaluation capacity whereby the demand for evaluation is increasing yet the supply for skilled evaluators is extremely low both in the public and private sectors (Phillips 2018). Studies by the Twende Mbele Initiatives during 2016 to 2018 and the Zenex Foundation 2018 provided insight into the evaluations demand and supply dynamics in South Africa (Phillips 2018; Zenex 2018). This phenomenon is also evident throughout sub-Saharan Africa. Ndagijimana (2016), stated that evaluation practices are developed in West Africa, but foreign and expatriate evaluators are valued more than indigenous ones. African evaluators are needed not only to carry-out baseline and end-term project evaluations but also to curb the high cost of international evaluators. The greatest challenge is opportunities for emerging evaluators (EE) from Africa. Kiwujja and Mwolobi (2017) described a similar situation and plight in Uganda where they developed a concept note for YEEs. Hlaka (2019) convened a session at the AfrEA conference and had YEEs discuss their frustrations in the context of the lack of agreement on evaluator competencies. The South African Monitoring and Evaluation Association (SAMEA) (2019) developed an interest group on EE in 2019 that aims to support EE capacity development, to promote their inclusion in evaluations nationally, regionally and internationally, and to enable and facilitate their active and meaningful participation. The role of VOPEs to reach YEEs is critical (Ngwabi, Mpyana, \& Mapatwana 2020). Young and EE are individuals who meet at least one of the following criteria (EvalYouth 2016; Manyoba, Lado \& Mabhena 2019):

- $\quad$ under the age of 35 years

- belong to a local VOPE

- have less than 5 years of professional experience

- recent university graduates (5 years or less postgraduation) who are interested in joining the evaluation profession

- development professionals who have relevant technical knowledge and, within the past 5 years or less, have expressed an interest in becoming professional evaluators.

There are slight differences in emphasis, for example, SAMEA (2019) accepted that EE can be older than 35 years. Moreover, Department of Planning Monitoring and Evaluation (DPME 2020) and Hlaka (2019) attested to the confusion that is evident in the interpretation of YEEs.

\section{Purpose}

Following the information gathered during the first phase, incorporating the voices and needs of YEEs was deemed an important second step. Thus, the purpose of this study is to understand the needs of African YEEs regarding gender responsive evaluation capacity development.

\section{Research strategy, design, procedures and methods}

The study employed a self-administered quantitative survey to gather information regarding the current situation of gender responsive evaluation capacity in Africa. A survey written in both English and French languages was developed based on the survey used for the previous phase of the study that looked at experienced evaluators' capacity. An electronic survey using the SurveyMonkey platform was disseminated over a 7-day period in June 2018, deliberately targeting YEEs using the existing YEEs network in Africa, the current VOPEs in Africa and AfrEA. It was distributed to email listservs such as AfrEA, SAMEA, EvalYouth, EvalGender+ and EvalIndigenous. Efforts were made to ensure that there was representation from all African regions. The process was repeated during a 7-day period to provide opportunity for all to respond. A non-probability voluntary response sampling strategy was used. The results are, therefore, not representative 
of all the African YEEs. Only responses from the respondents who fulfilled the definition of a YEE were included. A total of 72 respondents from 29 countries responded. Descriptive statistics, such as frequencies, were used to analyse the data. A researcher was assigned to analyse either French or English language responses. The French language responses were then translated into English language and all the researchers analysed the complete data set. Participation was voluntary and information was given about the study prior to completion of the survey during recruitment. Participants then consented to the use of data for research. Preliminary outcomes of the data analysis have been shared during International Development Evaluation Association (IDEA) conference in 2017.

\section{Ethical considerations}

This article followed all ethical standards for research without direct contact with human or animal subjects.

\section{Results}

\section{Self-concept as young and emerging evaluator}

The purpose of the survey was to understand the experiences, training gaps and needs regarding gender responsive evaluations of YEEs in Africa. The international definition of a YEE by EvalPartners (2016) is used to develop criteria for this study.

A total of 72 respondents completed the survey that was selfadministered over a 7-day period. There were slightly more male respondents (56\%) than females (44\%). Respondents were from 29 countries, of which majority (90\%) of the respondents from 23 were African countries, who were the expected target audience. Figure 1 illustrates the distribution of respondents across Africa.

A total of $74 \%$ (see Figure 2) of the YEE worked within the following four sectors: public sector (27\%), non-governmental organisation (NGO) (18\%), as researchers $(15 \%)$ and as independent consultants (14\%).

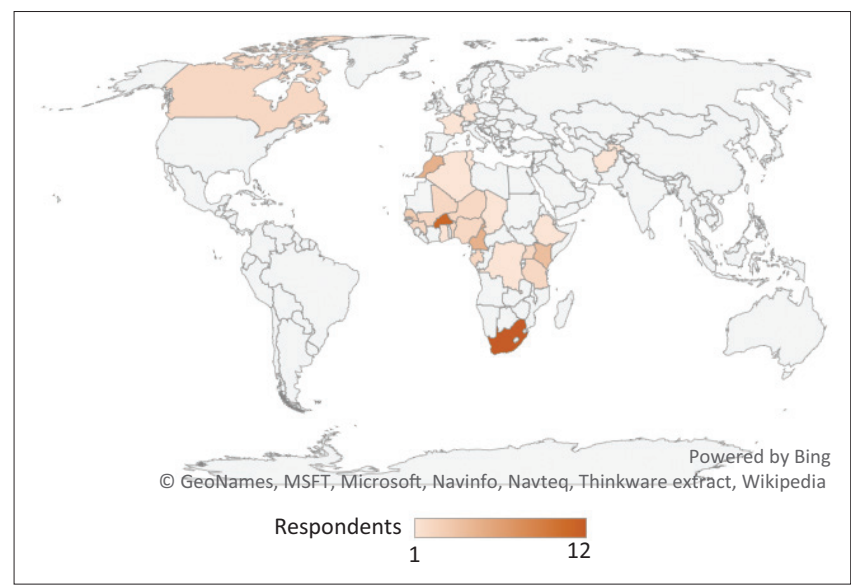

FIGURE 1: Geographical distribution of respondents $(N=72)$, majority across 23 African countries.
The majority (90\%) of the respondents fell within the definition of a YEE, with only a few falling outside this definition. For this article, the results from all respondents will be shared as most of the views are from YEEs. Based on Figure 3, most of the evaluators did not know that they are YEE or did not classify themselves as YEE.

\section{Young and emerging evaluators' participation in gender responsive evaluation or gender focus on evaluation trainings}

About one-third of respondents have either participated $(34.3 \%)$ in training programmes or programmes in gender responsive evaluation or gender focus on evaluation, with another one-third $(34.3 \%)$ only knew about trainings but have participated in these, and the last one-third (31.4\%) neither knew nor have participated in these programmes (see Figure 4). This highlights that there is a need for more gender responsive evaluation training of YEEs in Africa.

The types of training that respondents know of or have participated in are either virtual or face-to-face events. Of the 42 respondents that knew of or attended trainings, over half $(57 \%)$ attended or knew of face-to-face trainings, with fewer than $21 \%$ only attended or knew of virtual trainings. In addition, another $21 \%$ knew of or attended

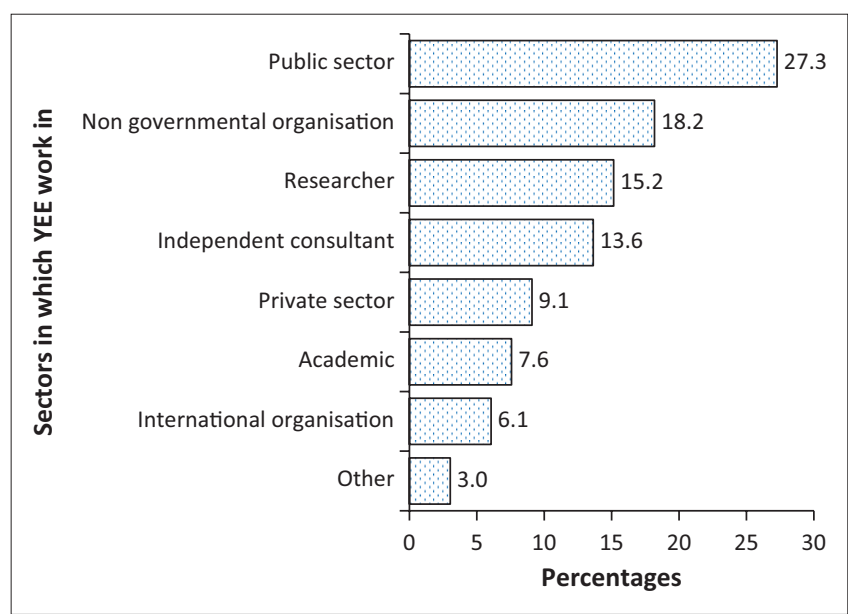

FIGURE 2: Sector-wise work area of the respondents $(n=66)$.

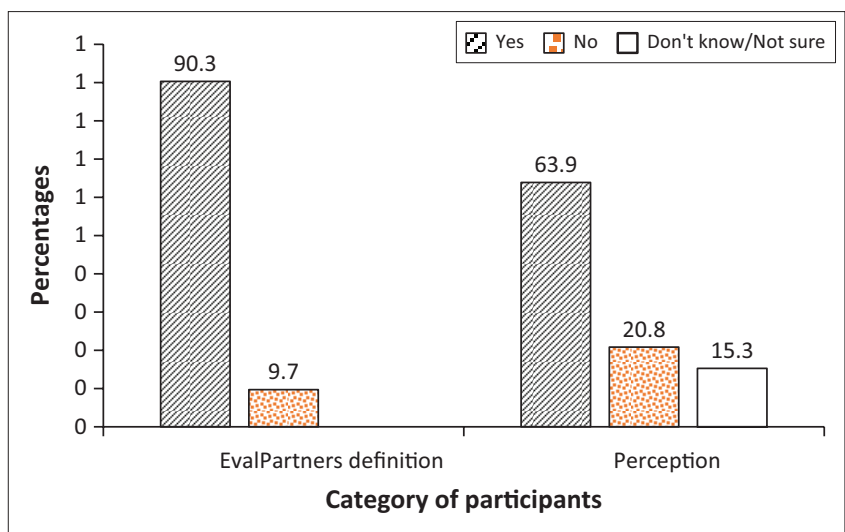

FIGURE 3: Category of participants according to EvalPartners definition and participants' perception. 
both face-to-face and virtual gender responsive evaluation trainings.

To investigate the specific gaps in capacity building, respondents were given 10 themes to rank according to importance (see Figure 5). There were four themes that were ranked as the most important by the survey respondents. Firstly, the theme 'applying the gender perspective as a quality criterion to all types of policies, programmes and projects' was ranked as the most important by $42 \%$ of the respondents. Secondly, 'applying participatory methods for the construction of collective knowledge and the empowerment of communities' was ranked by $40 \%$ of the respondents, as most important theme. Thirdly, 38\% of the respondents felt that the theme, 'analyse how gender inequality is articulated with other inequalities depending on the contexts and the intervention sector' was important; and lastly, 33\% ranked the theme 'generate analyses, conclusions, recommendations and lessons learned that serve to promote change in gender relations' as important.

The themes are similar to the findings of phase one study that targeted established evaluators in Africa. Both groups indicated that the most important theme to be addressed

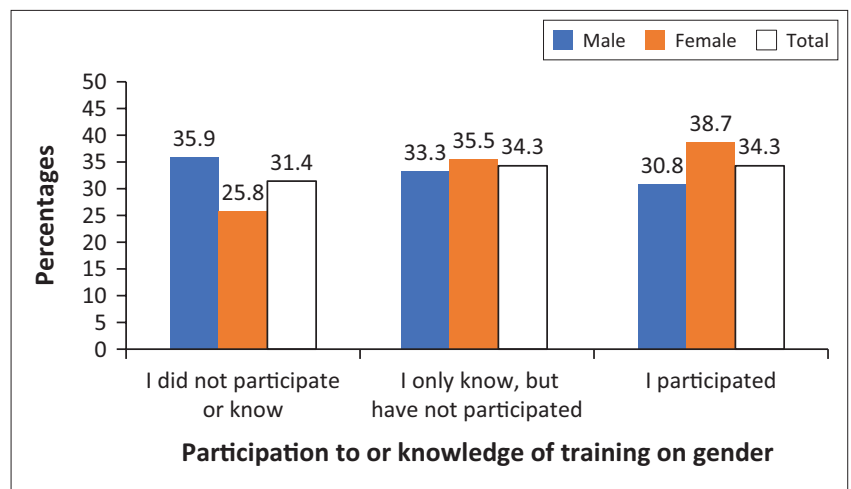

FIGURE 4: Participation in training on gender responsive training. is: 'apply the gender perspective as a quality criterion to all types of policies, programmes and projects'. The YEE indicated that the theme 'apply participatory methods for the construction of collective knowledge and the empowerment of communities' is the second most important to them, whilst it was the third most important for the established evaluators. These themes can be addressed in the same training session targeting both established and EEs, and do not need separate training sessions for YEE.

\section{Training needs on culturally responsive evaluations}

A majority (82\%) of the respondents identified having specific training needs on culturally responsive evaluation. These include, firstly, designing, conducting and integrating cultural values into an evaluation (especially in a culturally diverse continent as Africa) and, secondly, understanding and being more aware of what culturally responsive evaluation is, as there are not many trainings available on this topic. Respondents were also interested to learn how to develop evaluation tools and methods to adapt to cultural contexts and sharing case studies on successes of culturally responsive evaluations.

\section{Training needs on gender responsive evaluations}

Most of the respondents expressed a need for gender responsive evaluation training (83\%). The respondents wanted topics such as mainstreaming gender into evaluations and how to do gender sensitive and responsive evaluations to be included in the training. This includes not only basic training but also intermediary training and training of trainers on EFGR evaluations. They also indicated a need for a training on tools to conduct EFGR approaches, including practical techniques, designing EFGR evaluations, qualitative tools, gender context analysis and gender sensitive indicators.

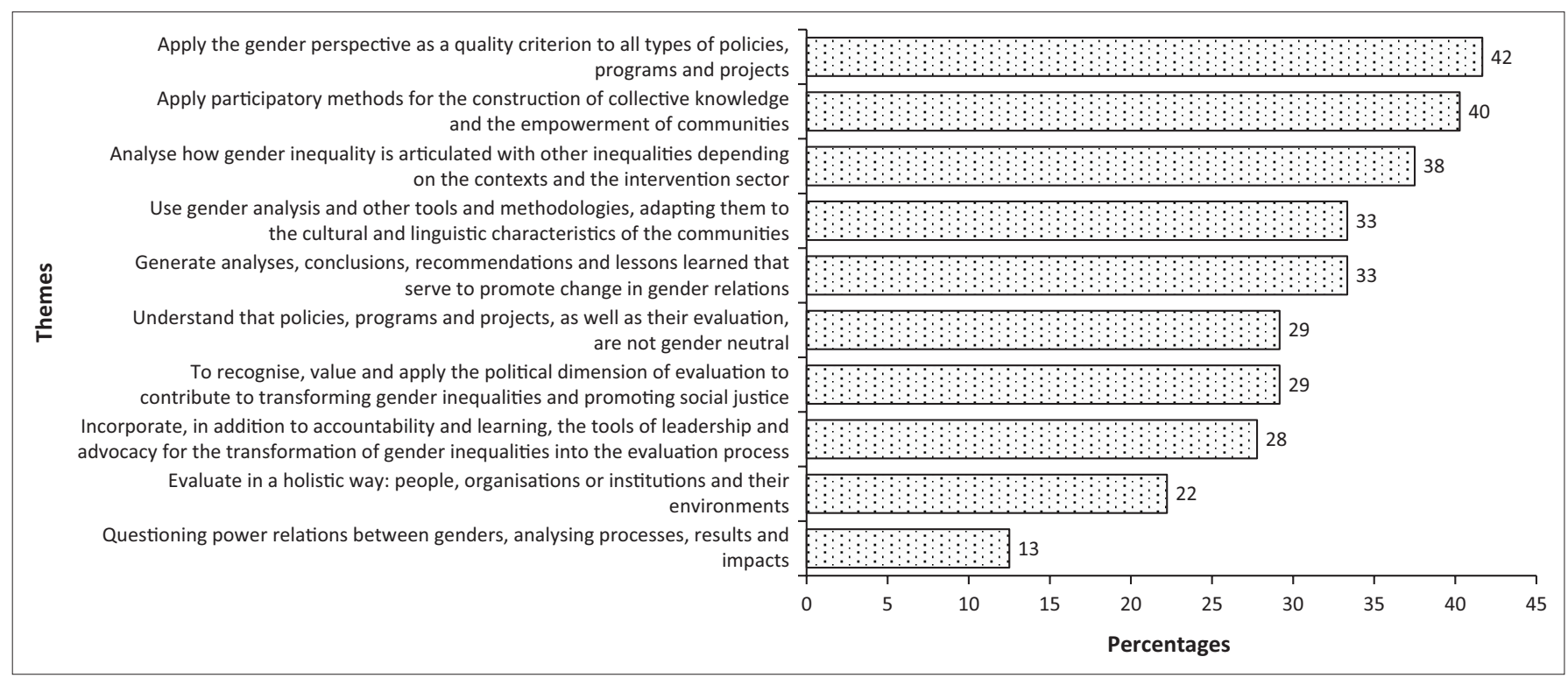

FIGURE 5: Training themes. 
Specific needs were also expressed to be able to conduct EFGR approaches for development and other projects, policies and national evaluation policies. These include evaluating gender interventions and being able to develop gender budgets. The sectors in which the YEE require training, to be able to conduct EFGR evaluations, are education, health, agriculture, community empowerment, children's rights, public administration, women's employment, women in parliament and government and women in higher education. The YEE expressed a need to have case studies and webinars sharing African experiences in EFGR approaches. They specifically needed to 'learn whilst doing' and mentorship opportunities.

\section{Discussion of the findings}

From the results it seems that evaluators in Africa do not regard themselves as YEE, either because of lack of awareness or lack of knowledge about the inclusion criteria of a YEE. Only $64 \%$ of the respondents identified themselves as a YEE, whilst $90 \%$ actually fulfilled the criteria. Similarly, Hlaka (2019) found that YEE are not clear about criteria for inclusion. This finding has been addressed since the survey in 2018, as many VOPEs (e.g. SAMEA, Burundi, Uganda) have since developed concept notes for inclusion of YEE interest groups; and YEE definitions and criteria are now more explicit.

Only a third of the respondents participated in some form of training. The most alarming aspect is the lack of awareness of any gender responsive evaluation training amongst a third of the respondents. Virtual training events became the norm during COVID-19 restrictions. This mode facilitates opportunities to reach more YEE and deliver training events throughout Africa even to those YEE who are not part of a local VOPE. There is now a wider acceptance of virtual meetings and trainings and improved technology and expertise to deliver online work sessions. Themes that are important for the YEE include gender as a quality criterion and application of participatory methods. These themes are generic evaluation criteria and can be addressed during gender training, but more importantly during general evaluation skills training. The other themes that were prominent relate to the achievement of gender equality in projects and programmes and are, therefore, related specifically to evaluation of gender focussed programmes.

The DPME (2020) and SAMEA survey for EE register development found that most of the EEs hold postgraduate qualifications, and they are mostly employed by government, civil society and the private sectors. The YEEs who responded to this study were similarly employed in different sectors.

An entry point for training delivery seems to be national VOPEs. In previous studies YEE mentioned that VOPEs and associations such as SAMEA are great platforms for skills development and networking (DPME 2020). This was reiterated by Ngwabi et al. (2020). The YEEsmentioned that they prefer learning in practical ways. Mentoring is a method that can enhance capacity in Africa in real world situations (Manyoba et al. 2019). International Development Evaluation Association has established a mentoring programme (Ponge et al. 2017). Mentoring opportunities by senior African gender evaluators seems to be solution. However, there is a lack of available and willing evaluators and this remains a challenge. For example, the DPME (2020) reported that less than $50 \%$ of established evaluators were willing to mentor EEs.

\section{Conclusions and recommendations}

The experiences of AGDEN allowed the organisation to make significant contributions to the development of a gender lens evaluations in Africa. However, in the light of EvalAgenda 2020 and the 'no-one left behind' principle of the SDGs, it is critical that the reach of these activities and influences are scaled-up. This first phase of the South-to-South project enabled AGDEN to reflect on the current EFGR curriculum and develop a new curriculum that includes and focuses on identified gaps and trends in the African continent. This second phase of the project, and the focus of this article, enabled the AGDEN to understand the needs and experiences of YEE on the gender responsive evaluation. The YEEs are eager to incorporate gender in their evaluations and to develop skills to enhance gender equality focussed projects and interventions.

The findings of this survey point to several gaps that need improvements. We, therefore, recommend the following:

- Marketing of evaluation capacity development activities will need to be specific in using criteria to identify YEE, as many YEEs do not identify as YEE.

- Efforts to include gender responsive evaluation theory and practice in current evaluation training curriculum would be a first step to enhance capacity.

- Virtual training events can include shorter webinars as awareness raising events and longer formal workshops or online self-paced courses to train YEE specifically on gender responsive evaluations.

- Gender responsive evaluation training should be targeting different sectors to be effective as YEE are employed in a variety of sectors and the topic cuts across sectors and disciplines.

- Voluntary Organisations for Professional Evaluation should be involved in promoting and offering mentorships for different contexts including private and public sectors. When considering gender responsive evaluation capacity for YEE, it will be the prerogative of thematic groups and VOPEs such as AGDEN in Africa and similarly other global South initiatives such as the Gender and Equality Network South Asia (GENSA).

- Targeted training should be carried out by VOPEs, who themselves should receive training from experienced organisations such as AGDEN. Established evaluators are encouraged to share case studies of EFGR evaluations in Africa. 


\section{Acknowledgements}

The authors would like to acknowledge Fazeela Hoosen who was part of the research team for the study and assisted in the Anglophone part of the data collection and analysis.

\section{Competing interests}

The authors declare that they have no financial or personal relationships that may have inappropriately influenced them in writing this article.

\section{Authors' contributions}

M.J.v.R. was the lead investigator. M.J.v.R. collected data from Anglophone and A.S.L. from Francophone contributors. A.S.L. analysed the data while M.J.v.R. integrated the data. M.J.v.R. and A.S.L. drafted the report.

\section{Funding information}

This study was supported by Peer-to-Peer grant from International Organization for cooperation in Evaluation (IOCE) and EvalPartners to the Africa Gender and Development Evaluators Network in 2018 as part of a larger South-to-South collaboration.

\section{Data availability}

Both raw and integrated versions of data are available from the corresponding author, M.J.v.R., upon reasonable request. This includes original French and translated English versions.

\section{Disclaimer}

The views and opinions expressed in this article are those of the authors and do not necessarily reflect the official policy or position of any affiliated agency of the authors, and the publishers.

\section{References}

Chigateri, S. \& Saha, S., 2016, A resource pack on gender transformative evaluations, Institute of Social Studies Trust, New Delhi.

Department of Planning, Monitoring and Evaluation (DPME) Republic of South Africa, 2020, The state of emerging evaluators in South Africa final draft survey report, DPME, Pretoria.
Espinosa, J., 2013, 'Moving towards gender-sensitive evaluation? Practices and challenges in international-development evaluation', Evaluation 19(2), 171-182. https://doi.org/10.1177/1356389013485195

EvalPartners, 2016, Global evaluation agenda 2016-2020, viewed 01 May 2021, from https://www.evalpartners.org/global-evaluation-agenda

EvalYouth, 2016, EvalYouth concept note, viewed 30 November 2018, from https:// vopetoolkit.ioce.net/es/resource/431-evalyouth-concept-note

Hlaka, T., 2019, 'IMBIZO: Sharing experiences of young emerging evaluators (YEEs)', in AfrEA 2019 conference, August 26, 2019, viewed 01 May 2021, from Articles IMBIZO: Sharing experiences of young emerging evaluators (YEEs): AfrEA 2019 Conference - Wits University.

Jansen van Rensburg, M.S. \& Blaser Mapitsa, C., 2017, ‘Gender responsiveness diagnostic of national monitoring and evaluation systems - methodological reflections', African Evaluation Journal 5(1), a191. https://doi.org/10.4102/aej.v5i1.191

Kiwujja, V. \& Mwolobi, T., 2017, 'The young and emerging evaluators program (YEE program): A concept note for increasing evaluation capacities in Africa', viewed 01 May 2021, from The Young and Emerging Evaluators Program (YEE Program): A concept note for Increasing Evaluation Capacities in Africa | Dr. Victor Kiwujja and Theodorah Mwolobi - Academia.edu

Loye, A., 2019, 'Gender responsive evaluation in the context of the sustainable development goals', eVALUation Matters Fourth Quarter, 34-43.

Manyoba, M., Lado, S. \& Mabhena, N., 2019,'A journey through experience mapping professional development pathways for YEEs', in AfrEA conference, viewed 01 May 2021, from Young and Emerging Evaluators - Mayibongwe Manyoba \& Susan Lado (slideshare.net).

Ndagijimana, J., 2016, Evaluation for Africa - A young evaluator's wish, viewed 01 May 2021, from Evaluation for Africa - A young evaluator's wish | EVALUATION FOR AFRICA (africaevaluation.org).

Ngwabi, N.T., Mpyana, O.G. \& Mapatwana, A., 2020, 'Reflections from emerging evaluators in shaping Voluntary Organizations for Professional Evaluation capacity-building initiatives', African Evaluation Journal 8(1), a509. https://doi. org/10.4102/aej.v8i1.509

Phillips, S., 2018, Diagnostic on the supply and demand of evaluators in South Africa Diagnostic Report, Twende Mbele, Johannesburg.

Ponge, A., Adesoba, T.P., Tammam, A. \& Gurung, T.D., 2017, 'Mentoring emerging evaluators - Sharing experiences from the Global South', in R.D. Van den Berg, I. Naidoo \& S.D. Tamondong (eds.), Evaluation for agenda 2030: Providing evidence on progress and sustainability, pp. 103-115, IDEAS, Exeter.

South African Monitoring and Evaluation Association (SAMEA), 2019, SAMEA emerging evaluators programme concept note, viewed 30 April 2021, from https://www.samea.org.za/summernotefile/dump?summernotefile_id=124

Tirivanhu, P. \& Jansen van Rensburg, M., 2018, 'An assessment of the gender esponsiveness of national monitoring and evaluation systems in South Africa', Development Southern Africa 35(2), 163-178. https://doi.org/10.1080/037683 5X.2017.1396443

United Nations, 2015, Sustainable development goals (SDGs), viewed 30 April 2018, from THE 17 GOALS | Sustainable Development (un.org).

United Nations Evaluation Group, 2014, Integrating human rights and gender equality in evaluation, viewed 21 November 2018, from http://www.unevaluation.org/ document/detail/1616

UN Women, 1995, Beijing declaration, UN Women, New York.

UN Women, 2015, UN women evaluation handbook: How to manage genderresponsive evaluation, viewed 21 November 2018, from UN Women Evaluation Handbook: How to manage gender-responsive evaluation, UN Women, New York.

Wokadala, J., 2016, Gender responsiveness diagnostic report of national monitoring and evaluation systems in Uganda, Twende Mbele, Johannesburg.

Zenex Foundation, 2018, Monitoring and evaluation capacity: A landscape analysis, viewed 21 November 2018, from https://www.zenexfoundation.org.za/images/ Final_Report_on_Landscape_Study 29_August_2018_LD.pdf 